\title{
Prenatal exposure to exogenous progesterone adversely affects fetal development in Albino rats
}

Hend M. Tag ${ }^{1,2^{*}}$, Rania Abdelrahman Elgawish ${ }^{3}$, Hala M. Ebaid ${ }^{1}$, Mona Abdel-Rahman ${ }^{1}$ and Heba M. A. Abdelrazek ${ }^{4}$

\begin{abstract}
Background: The current study was carried out to investigate the effects of exogenous progesterone on fetal development in rats.

Results: Placental weights did not vary in control and treated groups. Fetal weights were significantly reduced in the low- and high-dose progesterone groups. Fetal CVL was significantly reduced in both treatment groups compared to control group. In fetuses that received maternal treatment with low- and high-dose progesterone, several parts of the fetal skeleton showed incomplete ossification. Alkaline phosphatase was decreased in the bones of fetuses born to progesterone-treated dams. The testes and ovaries of the fetuses of the dams treated with low and high doses of progesterone showed degenerative seminiferous tubules and failed sex cord development into primordial follicles, respectively.

Conclusions: The administration of exogenous progesterone during pregnancy adversely influences fetal growth, skeletal construction, and sex organ development.
\end{abstract}

Keywords: Fetuses, Progesterone, Rats, Skeletal defects, Visceral organs

\section{Background}

Progesterone is used therapeutically in patients with infertility, hypoestrogenism, and secondary amenorrhea (Warren \& Shantha, 1999). Moreover, it is also prescribed in the treatment and management of several reproductive conditions, including threatened abortion, recurrent miscarriage, luteal phase maintenance in assisted reproduction programs, and threatened preterm labor (Di Renzo, Mattei, Gojnic, \& Gerli, 2005). An elevated progesterone concentration during corpus luteum formation may affect the developing embryo. An early rise in progesterone has been reported to alter the pattern of protein synthesis and

\footnotetext{
* Correspondence: hendmaarof1@yahoo.com

${ }^{1}$ Department of Zoology, Faculty of Science, Suez Canal University, Ismailia, Egypt

${ }^{2}$ Department of Biology, College of Science and Art, University of Jeddah Branch of Khulais Governorate-Girls Section, Jeddah, Saudi Arabia Full list of author information is available at the end of the article
}

secretion in cattle (Garrett, Geisert, Zavy, \& Morgan, 1988). Moreover, elevations in early circulating progesterone concentrations increase the embryo developmental rate (Garrett et al., 1988).

Check, Rankin, and Teichman (1986) and Rock et al. (1985) studied the effect of progesterone on the rate of congenital malformations in fetuses and found no relationship between the incidence of malformations and progesterone exposure. However, none of these studies have adequately addressed the hypothesis that progesterone affects the developing embryo. Rock et al. (1985) examined 93 women who received progesterone treatment during the first trimester; only 2 of them had fetuses with congenital malformations. In the study by Check et al. (1986), which investigated 382 women who received progesterone, only 5 had fetuses with congenital malformations.

There is scarce information concerning the dose of progesterone during pregnancy and its effect on fetal
Springer Open
() The Author(s). 2021 Open Access This article is licensed under a Creative Commons Attribution 4.0 International License, which permits use, sharing, adaptation, distribution and reproduction in any medium or format, as long as you give appropriate credit to the original author(s) and the source, provide a link to the Creative Commons licence, and indicate if changes were made. The images or other third party material in this article are included in the article's Creative Commons licence, unless indicated otherwise in a credit line to the material. If material is not included in the article's Creative Commons licence and your intended use is not permitted by statutory regulation or exceeds the permitted use, you will need to obtain permission directly from the copyright holder. To view a copy of this licence, visit http://creativecommons.org/licenses/by/4.0/. 
development as well as lacking of specific data on prenatal fetal exposure to excess progesterone. Moreover, the findings of previous studies examining existing animal models are contradictory that is why the present study aimed to determine the effects of two relevant therapeutic doses of progesterone during gestation on maternal weight gain, fetal development, fetal skeletal defects, and the histopathology in fetal sex organs. Subsequently, this will open a new research window to investigate the safety margin of using progesterone during pregnancy.

\section{Methods}

\section{Animal care}

This study was carried out on 30 adult virgin female rats and 9 male albino rats. Their weights ranged from 210 to $250 \mathrm{~g}$. Rats were obtained from Laboratory Animal House at the Faculty of Veterinary Medicine, Suez Canal University, Ismailia, Egypt. All rats were housed in well-ventilated plastic cages (3 rats per cage) with appropriate humane care. Rats were maintained at a room temperature of $25^{\circ} \mathrm{C}\left( \pm 1^{\circ} \mathrm{C}\right)$ and under a natural daylight cycle. Before the beginning of the experiment, the rats were kept for acclimatization for 2 weeks. They were fed on standard rodent pellets and given water ad libitum throughout the experimental period. Pregnant females $(n=27)$ were divided into 3 groups $(9$ animals per group). The control group was injected with corn oil. The procedures of the current study were carried out based on the ethical guidelines for the use of animals in laboratory experiments of the Faculty of Veterinary Medicine, Suez Canal University, Egypt (Approval number $\neq 2019016$ ).

\section{Breeding procedures}

The estrous cycle was checked by daily cytological examination of vaginal smears for 3 successive cycles (Ekambaram, Kumar, \& Joseph, 2017). Smears from the vagina were obtained from female rats $(n=30)$ early in the morning one time daily. The smears were dried with a flame, stained for 1 min with methylene blue (Sigma chemical Co., USA), and examined under a microscope to determine the stage of the estrous cycle. Females with 3 successive regular cycles $(n=27)$ were selected for this study, while those with irregular cycles $(n=3)$ were excluded. The females in proestrus with regular cycles were kept with males at a ratio of one male to 3 females per cage. Mating was confirmed by the presence of sperm in the vaginal smear or the presence of a vaginal plug which was designated as the zero day of pregnancy (Piesta, Maj, \& Chelmonska-Soyta, 2009).
Progesterone treatment and dose calculation

Progesterone was used in the present study in the form of Prontogest ${ }^{\circ}$, which was produced by the Egyptian International Pharmaceuticals Industries Company. Each ampoule contained $100 \mathrm{mg} / 2 \mathrm{ml}$ progesterone. Prontogest was diluted with corn oil at a ratio of 1:1. The doses of the drug were calculated by extrapolating the recommended human therapeutic dose in the enclosed pamphlet to the rat dose on the basis of the body surface area ratio by referring to Paget and Barnes (1964). The low-dose treatment group was injected subcutaneously with $1.8 \mathrm{mg} / 200 \mathrm{~g}$ bw progesterone in corn oil starting on gestation day 1 (GD1). The high-dose treatment group was injected subcutaneously in the skin of the neck with $3.6 \mathrm{mg} /$ $200 \mathrm{~g}$ bw progesterone in corn oil starting on GD1. Both doses were chosen according to the recommended therapeutic levels of progesterone mentioned in the enclosed manufacture pamphlet.

\section{Body weight gain}

The body weights of the control and treated dams were determined at the start and end of the experimental period. Maternal body weight gain was estimated by subtracting the final weight from the initial weight of the dams. The percent weight gain was calculated as follows: mean final weight - mean initial weight/mean initial weight $\times 100$.

\section{Percentage of implantation and fetal parameters}

The pregnant females in each group were sacrificed on GD20. The horns of the uterus were examined to determine the number of fetuses, resorbed fetuses, and corpora lutea in the ovaries to calculate the percentage of implantation. The number of implantation sites was determined as the sum of live fetuses and dead and resorbed fetuses (Figueiró-Filho et al., 2014). The percentage of implantation was calculated (Telefo, Tagne, Koona, Yemele, \& Tchouanguep, 2012) as follows: number of implantation sites/total number of corpora lutea $\times 100$. The placental weights for each group were recorded. The average fetal crown vertebral length $(\mathrm{CVL})$ and fetal weight were recorded as the distance from the fontanella to the base of the tail at GD20.

\section{Morphological malformations and skeletal preparation} Morphological malformations in the fetuses were observed carefully, and photographs of the fetuses born to control dams and dams treated with low and high doses of progesterone were taken. Additionally, the skeletal systems of the fetuses were examined for the presence or absence of ossification centers and for the rate of bone defects in the skull, limbs, and 
girdles. For this purpose, the skin, viscera, adipose tissue, and eyes were detached from the fetuses from the different experimental groups, and the remaining fetuses were kept in 95\% ethyl alcohol for 4 days followed by acetone for 1 day to remove the fat. Fetuses were double-stained for cartilage and bone (Alizarin red $\mathrm{S}$ plus Alcian blue staining) according to the method described by Mohsen, Esfandiari, Rabiei, Hanaei, and Rashidi (2013). Briefly, $10 \mathrm{ml}$ of staining solution was used for staining skeleton of each fetus that composed of equal amount (one volume) of $0.3 \%$ filtered Alcian blue in $70 \%$ ethanol, $0.1 \%$ filtered Alizarin red S in $95 \%$ ethanol, and acetic acid that was added to 17 volume $70 \%$ ethanol. Then, the stained fetus was washed with water and placed in an ascending series of glycerol and $1 \%$ aqueous $\mathrm{KOH}$ solution and then preserved in 100\% glycerin. The stained preparations were carefully examined under a microscope to explore the different parts of the axial and appendicular skeleton. Photographs were taken from all fetuses, and any skeletal abnormalities were recorded. The incidence of congenital malformations in the control fetuses and fetuses maternally treated with low or high doses of progesterone were examined according to Makris et al. (2009).

\section{Alkaline phosphatase analysis}

The bones of 6 fetuses in each group were dissected and cleaned carefully to remove skin and muscles as well as other tissues. The dissected bones were washed thoroughly using phosphate-buffered saline (PBS) to remove the blood. Homogenization was carried out in PBS ( $\mathrm{pH} 7.4$ ) at a ratio of $1 \mathrm{~g}$ of bone tissue to $5 \mathrm{~mL}$ of PBS. The mixture was centrifuged at $4000 \mathrm{rpm}$ for $15 \mathrm{~min}$ at $4{ }^{\circ} \mathrm{C}$. The supernatant was then separated and kept at $-80{ }^{\circ} \mathrm{C}$ for alkaline phosphatase (ALP) analysis. ALP activity was assayed kinetically using the ALP Kinetic UV method (Cat \# no. ALP 101090, BioMed, Hannover, Germany) at an absorbance of 405 .

\section{Histopathology}

Reproductive organs (testes and ovaries) as well as fetal cartilage were collected and fixed in $10 \%$ formalin buffer saline. They were gradually dehydrated and then embedded in paraffin wax. Several $5 \mu \mathrm{m}$ sections from each fetus were cut and then stained with hematoxylin and eosin stain (H\&E) for histopathological examination (Bancroft \& Gamble, 2008).

\section{Statistical analysis}

One way ANOVA (GraphPad prism software, version 7, San Diego, USA) was used for comparison between control, low, and high-treated progesterone groups. Data were expressed as the mean \pm SEM. The results were considered significant when $P$ was less than 0.05 .

\section{Results \\ Body weight gain and implantation}

The maternal weight gain of the low- and high-dose progesterone-treated pregnant dams was not significantly different from that of the control dams. The implantation percentage of the low-dose progesterone-treated pregnant dams was not significantly increased as compared with that of the control (Table 1).

\section{Placental weight and fetal parameters}

The average placental weights showed non-significant $(P>0.05)$ variation between control and progesteronetreated dams. The treated pregnant dams exhibited no significant changes in their litter number/dam. The fetal CVL was decreased significantly $(P<0.001)$ in fetuses born to dams treated with low and high dose of progesterone compared to that in control ones. The fetal weight was greatly reduced $(P<0.001)$ in the group of fetuses in the high-dose maternal progesterone treatment group compared to other groups of fetuses (Table 2).

\section{Gross morphology}

Control group displayed normal morphology. However, fetus maternally treated with low dose of progesterone showed leptocephaly, sclerosis, and acromelia in the forelimb as well as acromelia and symmelia in the hindlimb. The fetus maternally treated with high dose of progesterone revealed acromelia in the forelimb, kinked tail in runt fetuses as well as cutis lesion (Fig. 1; Table 3).

\section{Fetal malformations and skeletal studies}

The fetuses in the control group showed the lowest number of congenital anomalies compared to the fetuses in both maternally treated progesterone groups. Deformities of the hind limbs were the most common fetal anomalies in low and high progesterone treatment groups (Table 4).

Fetuses with high dose maternally treated progesterone exhibited generalized incomplete ossification all over the skeleton. Incomplete ossification of the skull roof (nasal, frontal, parietal, and interparietal bone) especially in high-dose progesterone-treated group was observed (Fig. 2). Additionally, high incidence of incomplete ossification of vertebral centrum as well as incomplete ossification of forelimb of manubrium and sternebrae were noticed in the latter group. The fore- and hindlimbs as well as their 
Table 1 Changes (mean \pm SE) in the maternal weight gain (g) and implantation (\%) in pregnant albino rats after injection of low and high doses of progesterone

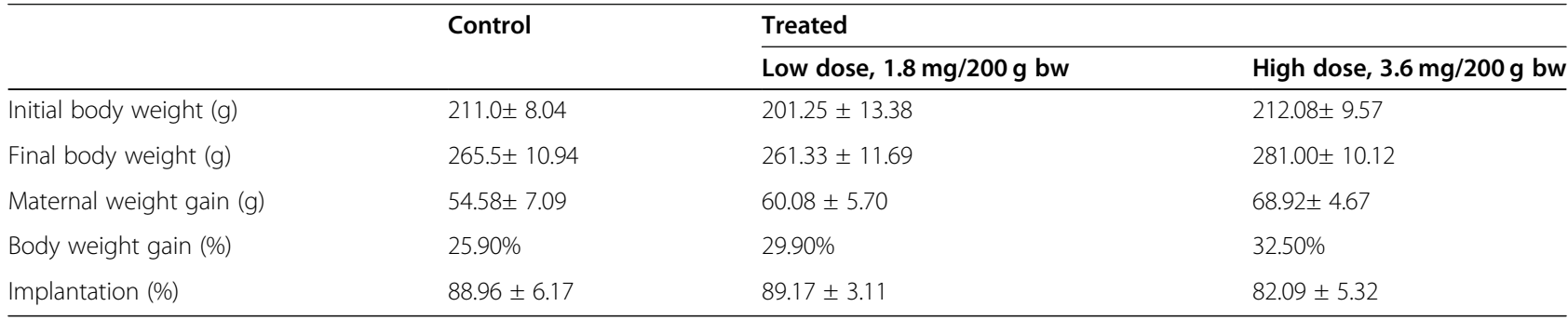

phalanges showed incomplete ossification with higher incidence in high-dose progesterone-treated group (Table 4).

The control fetus showed well-ossified vertebral column. Moreover, the vertebral column of maternally treated fetus with low dose of progesterone showed incomplete ossification all over the vertebral column with incomplete ossification of vertebral centra in cervical, thoracic, lumbar, and sacral vertebrae. The vertebral column of fetus maternally treated with high-dose progesterone showed more pronounced incomplete ossification all over the vertebral column with unossified vertebral centra in cervical, thoracic, lumbar, and sacral vertebrae. Also, unossified caudal vertebrae are observed (Fig. 3a). The control fetus showed fully ossified sternebrae. Additionally, the fetal rat sternum maternally treated with low-dose progesterone exhibited lesspronounced incomplete ossification of ribs and manubrium. However, the fetal rat sternum maternally treated with high-dose progesterone showed more pronounced incomplete ossification of the sternebrae with unossified manibrum. Also, xiphoid process shows incomplete ossification (Fig. 3b).

\section{Fore- and hindlimbs, pectoral, and pelvic girdles}

The control showed fully developed forelimbs. The fetuses maternally treated with low- and high-dose progesterone showed less and more pronounced incomplete ossification of the forelimbs, respectively (Fig. 4a). The control showed fully developed ilium, iliac crest, pubis "anterior bone," ischium "posterior bone," obturator foramen, femur, patella, tibia, fibula, tarsus, metatarsus, and phalanges. The fetuses maternally treated with low-dose progesterone show incomplete ossification of metatarsals and phalanges. Fetuses maternally treated with high-dose of progesterone demonstrated more pronounced incomplete ossification in the pelvic girdle parts and unossified metatarsus and phalanges (Fig. 4b).

\section{Alkaline phosphatase activity}

ALP activity declined significantly in the bones of the fetuses born to dams treated with high $(P<0.01)$ or low $(P<0.05)$ doses of progesterone compared to those of the control fetuses (Table 2).

\section{Histopathology}

The fetal rat testes of the control group showed a normal architecture for the seminiferous tubules and interstitial tissue. The fetuses maternally treated with lowdose progesterone showed degenerated seminiferous tubules. The fetuses maternally treated with high-dose progesterone showed hemorrhage between the seminiferous tubules and congested blood vessels, and most seminiferous tubules have an irregular degenerate pattern. The ovaries of the control had a normal architecture of well-developed primordial follicles. However, the

Table 2 Changes (mean \pm SE) in placental weight, fetal length, weight, and number of fetuses maternally treated with low and high doses of progesterone treatment groups

\begin{tabular}{llll}
\hline & Control & Treated & High dose, 3.6 $\mathbf{~ m g / 2 0 0 ~ g ~ b w ~}$ \\
\cline { 3 - 4 } & & Low dose, $\mathbf{1 . 8} \mathbf{~ m g / 2 0 0 ~ g ~ b w ~}$ & $0.56 \pm 0.01$ \\
\hline Placental weight (g) & $0.57 \pm 0.01$ & $0.54 \pm 0.01$ & $3.47 \pm 0.01^{\mathrm{b}}$ \\
Fetal CVL (cm) & $3.60 \pm 0.01^{\mathrm{a}}$ & $3.50 \pm 0.01^{\mathrm{b}}$ & $3.21 \pm 0.05^{\mathrm{b}}$ \\
Fetus weight (g) & $3.56 \pm 0.03^{\mathrm{a}}$ & $3.53 \pm 0.03^{\mathrm{a}}$ & $6.63 \pm 0.02$ \\
No. of litters/dams & $6.73 \pm 0.02$ & $6.84 \pm 0.02$ & $135.40 \pm 5.70^{\mathrm{b}}$ \\
ALP (unit/g) & $262.00 \pm 19.90^{\mathrm{a}}$ & $185.10 \pm 9.90^{\mathrm{b}}$ &
\end{tabular}

Superscript letters "a" and " $\mathrm{b}$ " represent a significant difference $(P<0.05)$ between the control and treatment groups 


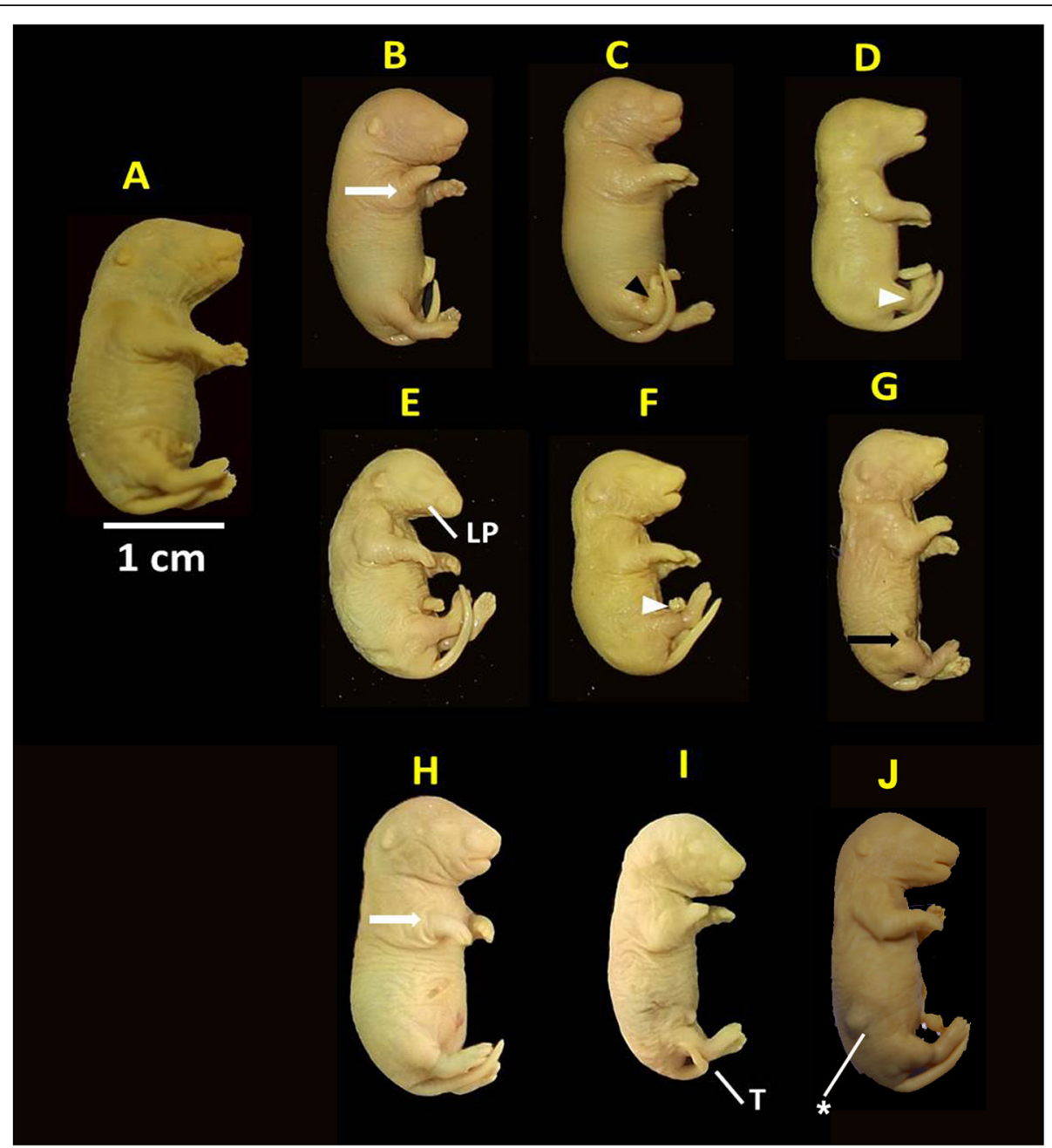

Fig. 1 Photomacrograph GD 20 fetal rat shows the external morphology. a Control group displayed normal morphology. b-g Fetus maternally treated with low-dose of progesterone $(1.8 \mathrm{mg} / 200 \mathrm{~g} \mathrm{bw})$, b fetus with acromelia in the forelimb (white arrow), e fetus exhibited leptocephaly (LP) and sclerosis, c runt fetus, $\mathbf{d}$ and $\mathbf{f}$ hindlimb displayed symmelia (white arrow head). $\mathbf{f}$ Fetus with acromelia in hind limb white arrow head). $\mathbf{h}-\mathbf{j}$ Fetus maternally treated with high dose of progesterone $(3.6 \mathrm{mg} / 200 \mathrm{~g} \mathrm{bw}), \mathbf{h}$ Fetus revealed acromelia in the forelimb (white arrow), $\mathbf{i}$ runt fetus with kinked tail (T) and $\mathbf{j}$ fetus with cutis lesion. Scale bar=1 cm

fetuses maternally treated with low-dose progesterone showed incomplete development and mild degeneration of sex cords. In addition, the fetuses maternally treated with high-dose progesterone showed poorly developed ovaries with an atrophied sex cord. The fetal cartilage of the control and maternally treated fetus with low-dose progesterone had normal chondrocyte. The fetal cartilage maternally treated with high-dose progesterone showed hypertrophied chondrocytes (Fig. 5).

\section{Discussion}

The progesterone hormone has been widely used in therapeutic purposes for numerous conditions, the management of amenorrhea and the prevention of threatened abortion and preterm labor. However, the direct effects of this therapeutic intervention on female health and their offspring have not been fully elucidated (Yassaee, Shekarriz-Foumani, Afsari, \& Fallahian, 2014). Thus, the current study handled several aspects on maternally treated fetuses that were not discussed collectively in one study before like malformations, morphometry, sex organs, and skeletal development with reference to skeletal fetal alkaline phosphatase activity. Moreover, this study reported novel findings on the adverse effect of therapeutic doses of progesterone commonly used in women during pregnancy and its effect on fetal development.

In this study, maternal exposure to progesterone nonsignificantly influenced body weight gain, and these results were consistent with those of Bartholomeusz and 
Table 3 Incidence of morphological anomalies in the control fetuses and fetuses maternally treated with low and high doses of progesterone

\begin{tabular}{llll}
\hline Parameters & Control & Low dose, $\mathbf{1 . 8} \mathbf{~} \mathbf{g} / \mathbf{2 0 0} \mathbf{g}$ bw & High dose, 3.6 $\mathbf{~ m} \mathbf{2} \mathbf{2 0 0} \mathbf{g} \mathbf{b w}$ \\
\hline No. of dams & 9 & 9 & 9 \\
No. of fetus/dam & 61 & 62 & 60 \\
No. of dams had abnormal fetus & $7 / 9$ & $9 / 9$ & $9 / 9$ \\
Anasarca & $0.01 \pm 0.00^{\mathrm{c}}(0.11 \% \pm 0.00)$ & $0.44 \pm 0.17^{\mathrm{b}}(7.40 \% \pm 2.92)$ & $1.88 \pm 0.11^{\mathrm{a}}(31.90 \% \pm 2.33)$ \\
Runt (small) & $0.22 \pm 0.14^{\mathrm{b}}(3.17 \% \pm 2.1)$ & $4.00 \pm 0.33^{\mathrm{a}}(64.02 \% \pm 4.78)$ & $5.00 \pm 0.40^{\mathrm{ac}}(82.59 \% \pm 3.95)$ \\
Hematoma & $0.22 \pm 0.14^{\mathrm{c}}(3.70 \% \pm 2.45)$ & $3.77 \pm 0.27^{\mathrm{b}}(60.85 \% \pm 4.63)$ & $4.66 \pm 0.28^{\mathrm{a}}(77.57 \% \pm 2.80)$ \\
Cutis lesion & $0.01 \pm 0.00^{\mathrm{b}}(0.11 \% \pm 0.00)$ & $0.66 \pm 0.16^{\mathrm{b}}(0.10 \% \pm 0.02)$ & $0.88 \pm 0.11^{\mathrm{a}}(15.03 \% \pm 1.99)$ \\
Symmelia (bent limb) & $0.02 \pm 0.00^{\mathrm{c}}(0.22 \% \pm 0.00)$ & $0.66 \pm 0.16^{\mathrm{b}}(10.58 \% \pm 2.66)$ & $2.44 \pm 0.17^{\mathrm{a}}(40.63 \% \pm 2.19)$ \\
Acromelia (short limb) & $0.01 \pm 0.00^{\mathrm{c}}(0.11 \% \pm 0.00)$ & $0.77 \pm 0.14^{\mathrm{b}}(0.12 \% \pm 0.02)$ & $2.00 \pm 0.00^{\mathrm{a}}(33.76 \% \pm 1.35)$ \\
Kinked tail & $0.01 \pm 0.00^{\mathrm{c}}(0.11 \% \pm 0.00)$ & $0.77 \pm 0.14^{\mathrm{b}}(00.12 \% \pm 0.02)$ & $2.44 \pm 0.17^{\mathrm{a}}(40.63 \% \pm 2.19)$ \\
Large genital tubercle & $0.02 \pm 0.00^{\mathrm{b}}(0.22 \% \pm 0.00)$ & $0.77 \pm 0.27^{\mathrm{b}}(10.60 \% \pm 4.74)$ & $2.33 \pm 0.28^{\mathrm{a}}(38.78 \% \pm 4.39)$ \\
Decreased anogenital distance & $0.02 \pm 0.00^{\mathrm{c}}(0.22 \% \pm 0.00)$ & $1.55 \pm 0.37^{\mathrm{b}}(25.40 \% \pm 6.38)$ & $3.88 \pm 0.45^{\mathrm{a}}(62.17 \% \pm 6.90)$ \\
\hline
\end{tabular}

Data was expressed as mean \pm SE and mean percent.

Different superscripts in the same row indicates significance at $P<0.001$

Table 4 Incidence of skeletal anomalies in the control fetuses and fetuses maternally treated with low and high doses of progesterone

\begin{tabular}{|c|c|c|c|}
\hline Anomalies & Control $(n=61)$ & $\begin{array}{l}\text { Low dose }(n=62), 1.8 \mathrm{mg} / 200 \mathrm{~g} \\
\text { bw }\end{array}$ & $\begin{array}{l}\text { High dose }(n=60), 3.6 \mathrm{mg} / 200 \mathrm{~g} \\
\text { bw }\end{array}$ \\
\hline Lordosis & $0.01 \pm 0.00^{c}(0.11 \% \pm 0.00)$ & $0.88 \pm 0.11^{\mathrm{b}}(14.29 \% \pm 1.81)$ & $2.77 \pm 0.14^{\mathrm{a}}(46.93 \% \pm 3.27)$ \\
\hline Vertebral unossified area & $\begin{array}{l}0.22 \pm 0.14^{c}(3.17 \% \pm \\
2.10)\end{array}$ & $0.88 \pm 0.11^{\mathrm{b}}(14.29 \% \pm 1.81)$ & $3.55 \pm 0.24^{a}(60.11 \% \pm 5.02)$ \\
\hline Skull roof incomplete & $0.02 \pm 0.00^{c}(0.22 \% \pm 0.00)$ & $1.22 \pm 0.14^{b}(19.31 \% \pm 1.75)$ & $3.44 \pm 0.17^{\mathrm{a}}(57.51 \% \pm 2.20)$ \\
\hline Incomplete ossification of sternebrae & $0.01 \pm 0.00^{c}(0.11 \% \pm 0.00)$ & $1.11 \pm 0.20^{\mathrm{b}}(17.99 \% \pm 3.39)$ & $3.11 \pm 0.26^{\mathrm{a}}(53.23 \% \pm 6.05)$ \\
\hline Hemisternebra (s) & $0.22 \pm 0.14^{c}(3.17 \% \pm 2.10)$ & $0.66 \pm 0.16^{\mathrm{b}}(10.58 \% \pm 2.66)$ & $1.88 \pm 0.11^{\mathrm{a}}(31.90 \% \pm 2.33)$ \\
\hline Incomplete ossification of vertebrae & $0.01 \pm 0.00^{\complement}(0.11 \% \pm 0.00)$ & $1.11 \pm 0.11^{\mathrm{b}}(17.99 \% \pm 1.94)$ & $2.88 \pm 0.35^{\mathrm{a}}(47.51 \% \pm 4.76)$ \\
\hline Incomplete ossification of scapula & $0.02 \pm 0.00^{\complement}(0.22 \% \pm 0.00)$ & $0.88 \pm 0.11^{\mathrm{b}}(14.29 \% \pm 1.81)$ & $2.55 \pm 0.17^{\mathrm{a}}(42.49 \% \pm 2.20)$ \\
\hline Incomplete ossification of humerus & $0.02 \pm 0.00^{c}(0.22 \% \pm 0.00)$ & $1.11 \pm 0.20^{\mathrm{b}}(17.46 \% \pm 2.77)$ & $2.55 \pm 0.17^{\mathrm{a}}(42.49 \% \pm 2.20)$ \\
\hline Incomplete ossification of radius and ulna & $0.01 \pm 0.00^{c}(0.11 \% \pm 0.00)$ & $1.33 \pm 0.23^{b}(21.16 \% \pm 3.60)$ & $2.55 \pm 0.17^{\mathrm{a}}(42.49 \% \pm 2.20)$ \\
\hline Incomplete ossification of carpal & $0.02 \pm 0.00^{\mathrm{b}}(0.22 \% \pm 0.00)$ & $0.77 \pm 0.27^{\mathrm{b}}(12.43 \% \pm 4.59)$ & $2.22 \pm 0.40^{\mathrm{a}}(36.19 \% \pm 6.10)$ \\
\hline Incomplete ossified metacarpal & $0.01 \pm 0.00^{\complement}(0.11 \% \pm 0.00)$ & $1.44 \pm 0.17^{\mathrm{b}}(23.54 \% \pm 3.11)$ & $3.11 \pm 0.11^{\mathrm{a}}(52.49 \% \pm 2.69)$ \\
\hline Forelimb aphalangia (absent phalanx) & $0.01 \pm 0.00^{\mathrm{a}}(0.11 \% \pm 0.00)$ & $0.66 \pm 0.28^{a}(11.11 \% \pm 4.81)$ & $0.66 \pm 0.44^{a}(11.11 \% \pm 7.34)$ \\
\hline $\begin{array}{l}\text { Forelimb incomplete ossification of } \\
\text { phalanges }\end{array}$ & $0.02 \pm 0.00^{\complement}(0.22 \% \pm 0.00)$ & $2.44 \pm 0.17^{\mathrm{a}}(39.68 \% \pm 3.32)$ & $3.11 \pm 0.26^{\mathrm{ab}}(51.75 \% \pm 3.92)$ \\
\hline Femur incomplete ossification & $0.02 \pm 0.00^{\complement}(0.22 \% \pm 0.00)$ & $1.33 \pm 0.16^{\mathrm{b}}(21.69 \% \pm 2.92)$ & $3.00 \pm 0.00^{\mathrm{a}}(50.63 \% \pm 2.03)$ \\
\hline Tibia and fibula incomplete ossification (O) & $0.01 \pm 0.00^{\mathrm{b}}(0.11 \% \pm 0.00)$ & $1.33 \pm 0.16^{\mathrm{a}}(21.69 \% \pm 2.92)$ & $1.66 \pm 0.23^{\mathrm{ac}}(27.46 \% \pm 3.58)$ \\
\hline Incomplete ossification of tarsal & $0.02 \pm 0.00^{\mathrm{b}}(0.22 \% \pm 0.00)$ & $0.55 \pm 0.17^{b}(9.25 \% \pm 2.92)$ & $2.77 \pm 0.32^{\mathrm{a}}(46.19 \% \pm 5.05)$ \\
\hline Incomplete ossified metatarsal & $0.22 \pm 0.14^{c}(3.70 \% \pm 2.45)$ & $1.22 \pm 0.14^{\mathrm{b}}(19.31 \% \pm 1.75)$ & $3.66 \pm 0.23^{\mathrm{a}}(61.22 \% \pm 3.40)$ \\
\hline Hindlimb aphalangia (absent phalanx) & $0.01 \pm 0.00^{\mathrm{b}}(0.11 \% \pm 0.00)$ & $2.22 \pm 0.14^{\mathrm{b}}(3.70 \% \pm 2.45)$ & $2.33 \pm 0.52^{\mathrm{a}}(38.78 \% \pm 8.56)$ \\
\hline $\begin{array}{l}\text { Hindlimb incomplete ossification of } \\
\text { phalanges }\end{array}$ & $0.22 \pm 0.14^{\mathrm{b}}(3.70 \% \pm 2.45)$ & $1.77 \pm 0.36^{a}(28.57 \% \pm 6.03)$ & $3.00 \pm 0.60^{\mathrm{ac}}(50.00 \% \pm 9.83)$ \\
\hline
\end{tabular}




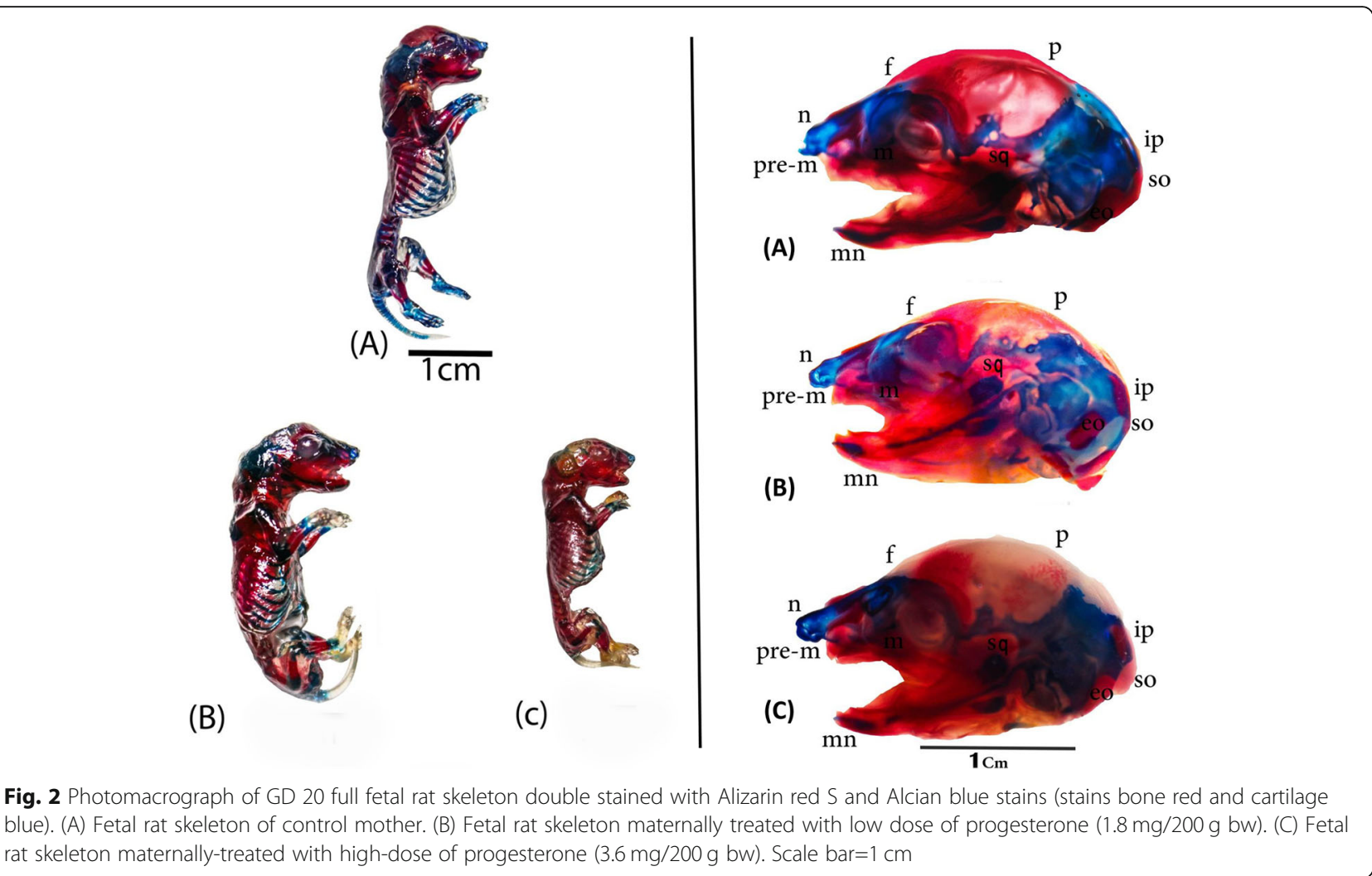

Bruce (1976). However, the numerical increase in the body weight gain was parallel with the findings of Bhatia and Wade (1989). The current results demonstrated that the increase in maternal weight gain from 29.9 to $32.5 \%$ after treatment with 1.8 and $3.6 \mathrm{mg} / 200 \mathrm{~g}$ bw progesterone, respectively, compared to $25.9 \%$ in the control group may be due to the promoting effects of progesterone on several hormones, including leptin (Augustine, Ladyman, \& Grattan, 2008), neuropeptide Y (Tovar et al., 2004), and cholecystokinin (Gutzwiller et al., 2000). These hormones could promote food intake to influence the metabolic status of the body in preparation for future lactation and the development of the fetus during pregnancy (Faas, Melgert, \& de Vos, 2010).

The implantation percent showed a non-significant change between the control and progesterone-treated dams. These results were in agreement with those of Chwalisz, Winterhager, Thienel, and Garfield (1999) while contradicting those of Harini, Sainath, and Reddy (2009a). The placental weight of the dams treated with low-dose progesterone decreased significantly. This result was contradictory to the findings of Bartholomeusz and Bruce (1976). The present study demonstrated significant adverse effects of maternal progesterone supplementation on fetal CVL compared with the control group. Furthermore, the fetal weight analysis revealed a marked reduction in the weights of fetuses maternally treated with high-dose of progesterone.
These results were in agreement with those of Resseguie et al. (1985) and Seegmiller, Nelson, and Johnson (1983). Carmichael et al. (2005) reported that the reduction in weights of fetuses from progesterone-treated dams was etiologically distinct. Controversially, Bartholomeusz and Bruce (1976) found that progesterone administration to dams had no effect on fetal weight.

It is impossible to evaluate the skeleton of late gestation rodent fetuses because major portion remains unossified and, subsequently, unstained with Alizarin red S. Failure to evaluate the cartilaginous portions of the skeleton may result in difficulties in identification of important abnormalities in skeletal morphology. Therefore, the double staining method for fetal skeletons was proposed several years ago by different investigators with minor differences in methodology (Menegola, Broccia, \& Giavini, 2001). In the current study, several congenital defects were recorded especially in the skeletal system with high prevalence of hindlimb defects. Janerich, Piper, and Glebatis (1974) were the first to report an association between maternal progestogen administration and limb reduction defects in infants. Of 108 women with an affected infant, 15 had received progesterone hormones. Additionally, Greenberg, Inman, Weatherall, Adelstein, and Haskey (1977) found an overall increase in anomalies following progestogen exposure; limb reduction 


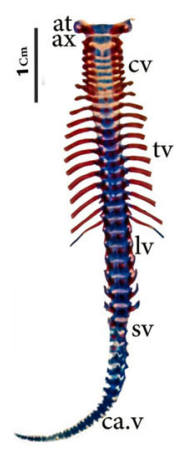

(A)

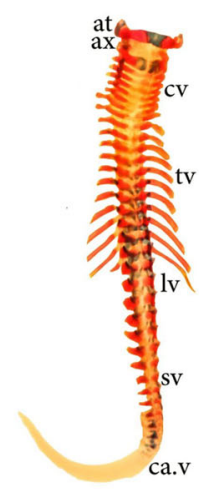

(B)

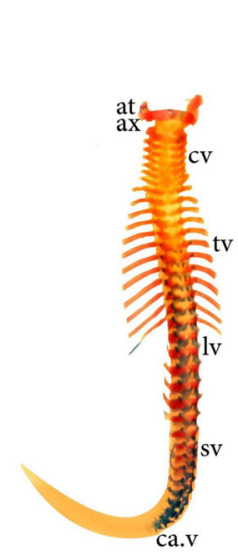

(C)

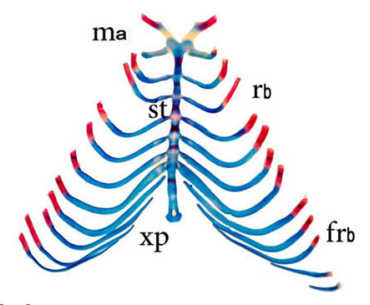

(A)

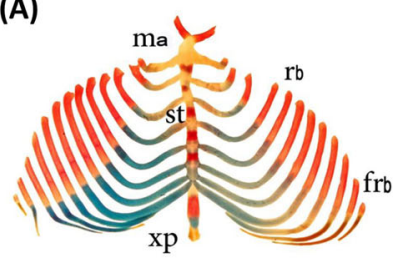

(B)

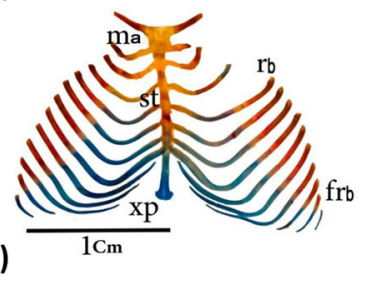

B

Fig. 3 a Fetal rat vertebral column double stained with Alizarin red S and Alcian blue. (A) The control shows well-ossified vertebral centra; parts of the neural arches of atlas (at); axis (ax); the remaining cervical vertebrae (cv); the thoracic (tv), lumbar (Iv), and sacral (sv) vertebrae; and the first one-third of the caudal vertebrae (ca.v). (B) The fetal rat vertebral column maternally treated with low dose of progesterone (1.8 mg/200 g bw) shows incomplete ossification all over the vertebral column with incomplete ossification of vertebral centra in cv, tv, IV, and sv. (C) The fetal rat vertebral column maternally treated with high-dose progesterone $(3.6 \mathrm{mg} / 200 \mathrm{~g} \mathrm{bw})$ shows more pronounced incomplete ossification all over the vertebral column with unossified vertebral centra in $\mathrm{Cv}, \mathrm{tv}, \mathrm{IV}$, and sv. Also, unossified caudal vertebrae are observed. b The fetal rat sternum double stained with Alizarin red S and Alcian blue. (A) The control shows six fully ossified sternebrae (st) and cartilaginous sternal portions of the ribs (rb), free ribs (frb), manubrium (ma), and xiphoid process (xp), which also shows that the cartilage-ossification ratio of the body of the ribs increased caudally as descending. (B) The fetal rat sternum maternally treated with low-dose progesterone (1.8 mg/200 g bw) exhibited less pronounced incomplete ossification of the ribs and manubrium. (C) The fetal rat sternum maternally treated with high-dose progesterone (3.6 $\mathrm{mg} / 200 \mathrm{~g}$ bw) shows more pronounced incomplete ossification of the sternebrae (st) with unossified manibrum. Also, xp shows

incomplete ossification

defects contributed to this increase. Moreover, a retrospective case-control study in Australia by Kricker, Elliott, Forrest, and McCredie (1986) recorded an association between oral contraceptive use and limb abnormalities.

The skeletal defects of the fetuses maternally treated with progesterone were manifested as delayed ossification of the parietal bone of the skull, incomplete ossification in most sternal bones. These results were in accordance with the survey performed by Lammer and Cordero (1986) on malformations associated with exposure to sex steroids, including progesterone exposure during pregnancy. The obtained data indicated deficient mineralization of the skeletal system of the fetuses. The current results suggested that progesterone treatment of pregnant dams could affect bone formation, mineralization, and cartilage formation leading to skeletal malformations. The explanation for the skeletal malformations is that progesterone can reduce $\mathrm{Ca}^{++}$deposition in the bone, enhance bone resorption in pregnant dams, and increase fecal $\mathrm{Ca}^{++}$excretion from fetuses, thus reduces their bone $\mathrm{Ca}^{++}$deposition (Harel et al., 2010). Moreover, the reduced ALP activity in the bones of progesterone-treated fetuses is suggestive of a bone catabolic status where ALP is a wellknown major bone mineralization regulator (Christenson, 1997). Additionally, ALP plays a crucial role in proosteoblastic cell differentiation and osteoblast development (Alborzi, Mac, Glackin, Murray, \& Zernik, 1996). Therefore, the reduction in bone ALP activity in low- and highprogesterone-treated fetuses is suggestive of the observed bone malformations in these two groups.

The current study demonstrated the adverse effects of maternal progesterone administration on the development of fetal sex organs. The male fetuses of the progesterone-treated dams exhibited testicular degeneration, edema, and blood vessel congestion. The effect seemed to be dose dependent. The current results were in agreement with those of Harini, Sainath, and Reddy 


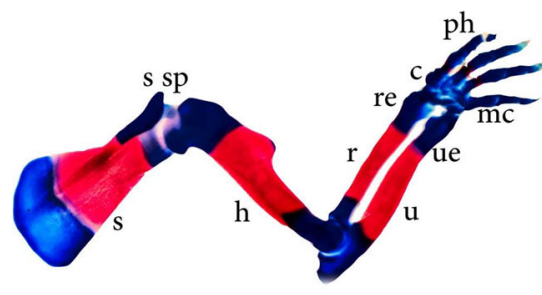

(A)
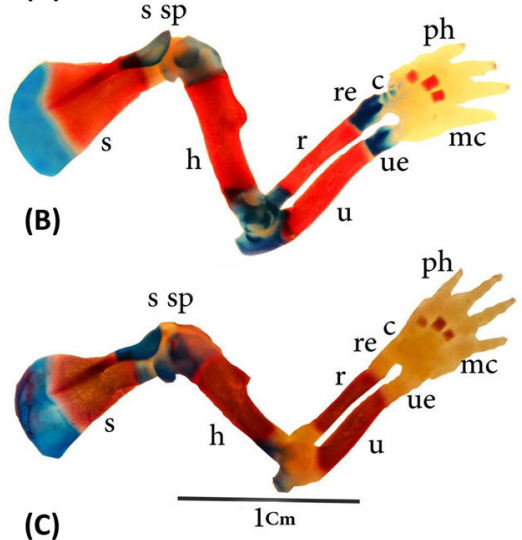

Fig. 4A

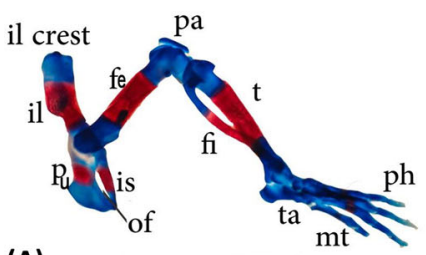

(A)
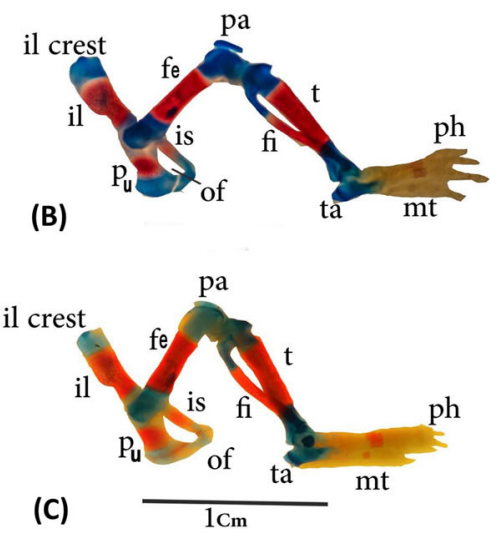

Fig. 4B

Fig. 4 a The fetal rat scapula and forelimb double stained with Alizarin red S and Alcian blue. (A) The control shows a fully developed scapula (s), scapular spine (ssp), humerus (h), radius (r), ulna (u), radial epiphysis (re), ulnar epiphysis (ue), carpals (c), metacarpals (mc), and phalanges (ph). (B) The fetuses maternally treated with low-dose progesterone ( $1.8 \mathrm{mg} / 200 \mathrm{~g}$ bw) shows less pronounced incomplete ossification of radial bone (re), ulnar bone (ue), humerus, and carpals. The phalanges (ph) are unossified. (C) The fetuses maternally treated with high-dose of progesterone (3.6 $\mathrm{mg} / 200 \mathrm{~g}$ bw) show more pronounced incomplete ossification of the humerus, re, ue, and c. The phalanges are unossified. $\mathbf{b}$ Half of the fetal rat pelvic girdle and the hindlimb double-stained with Alizarin red S and Alcian blue. (A) The control shows fully developed ilium (il), iliac crest (il crest), pubis "anterior bone" (pu), ischium "posterior bone" (is), obturator foramen (of), femur (fe), patella (pa), tibia (t), fibula (fi), tarsus (ta), metatarsus (mt), and phalanges (ph). (B) The fetuses maternally treated with low-dose progesterone $(1.8 \mathrm{mg} / 200 \mathrm{~g}$ bw) show incomplete ossification of metatarsals ( $\mathrm{mt}$ ) and phalanges (ph). (C) Fetuses maternally treated with high dose of progesterone $(3.6 \mathrm{mg} / 200 \mathrm{~g}$ bw) demonstrate more pronounced incomplete ossification in the pelvic girdle parts and unossified $\mathrm{mt}$ and $\mathrm{ph}$

(2009b) who reported testicular retrogressive changes in male offspring born to dams that were treated with hydroxyprogesterone hexanoate during gestation. A pharmacological dose of progesterone to dams can cross the placenta and pass to fetus (Yan et al., 2008). This crossed progesterone adversely influences the hypothalamic-pituitary axis (Ellinwood \& Resko, 1980; Pointis, Latreille, \& Cedard, 1980; Pointis, Latreille, Richard, D'Athis, \& Cedard, 1987), thus reducing fetal LH inducing testosterone levels. Additionally, progesterone has been proposed to have a direct local inhibitory effect on testicular testosterone production (Pointis, Latreille, Richard, D'Athis, \& Cedard, 1984). The reduced fetal testosterone level is attributed to the deteriorated testicular architecture that can adversely affect future male fertility and fecundity (Pushpalatha, Reddy, \& Reddy, 2003). The low and high progesterone doses delayed the development of sex cords into primordial follicles. These results were parallel to those of Kezele and Skinner (2003). They demonstrated the adverse impacts of progesterone on the development of ovarian primordial follicles in ovaries of rat neonates in vitro. The arrest of primordial follicle development crucially influences the subsequent transformation of these follicles into primary follicles immediately after delivery (Rajah, Glaser, \& Hirshfield, 1992). This transformation constitutes a crucial event for further normal ovarian physiology. Abnormalities in primordial follicle assembly possibly result in ovarian pathological conditions, such as premature ovarian failure (Kezele \& Skinner, 2003).

\section{Conclusions}

In conclusion, prenatal administration of exogenous progesterone at doses of 1.8 and $3.6 \mathrm{mg} / 200 \mathrm{~g}$ bw has adverse effects on morphology, skeletal construction of fetuses, and sex organs of male and female fetuses. These adverse alterations seemed to be dose-dependent. The finding of this study could be generalized to other animal species and human to clarify the effect of prenatal exposure of exogenous progesterone. However, further investigations should be carried out to assess the safety of a marginal progesterone dosage to avoid its side effects. 


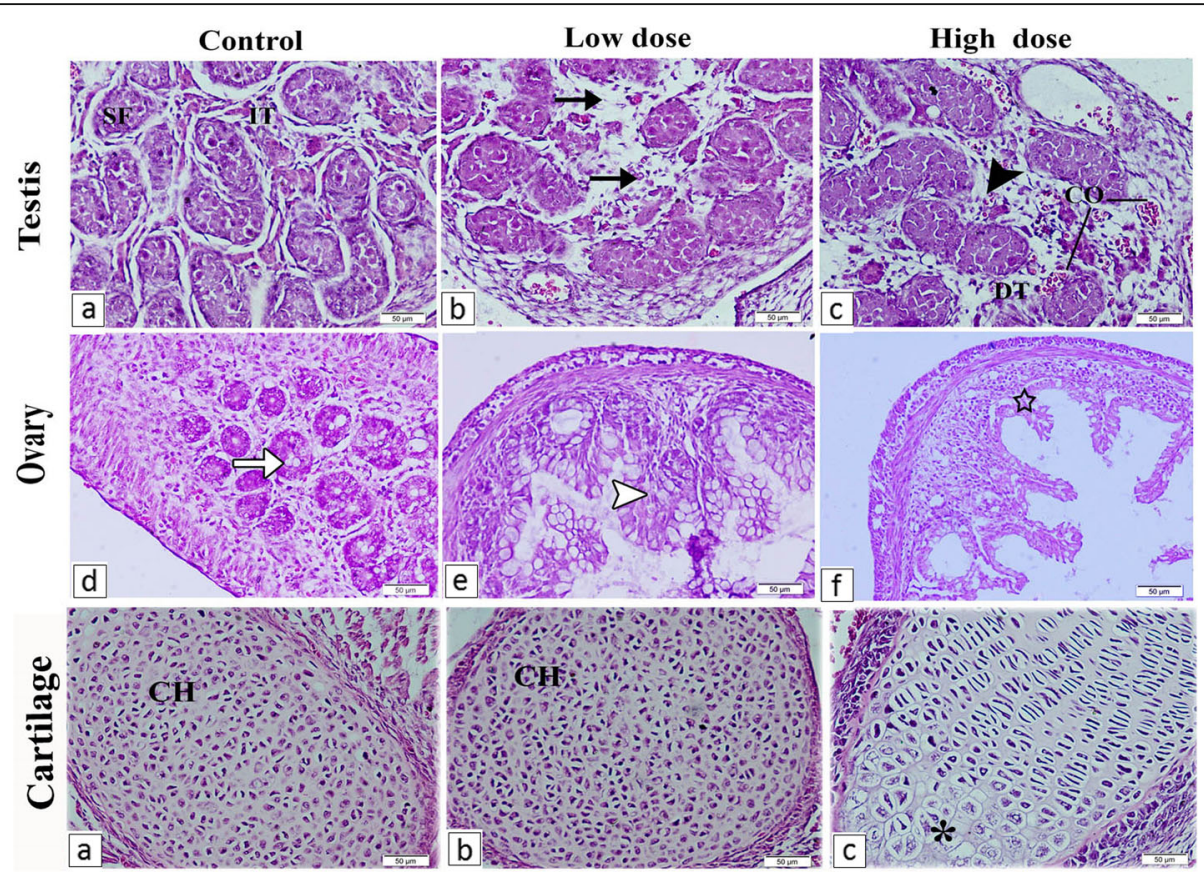

Fig. $\mathbf{5}$ a The fetal rat testis of the control group shows a normal architecture for the seminiferous tubules (SE) and interstitial tissue (IT). b The fetuses maternally treated with low-dose progesterone $(1.8 \mathrm{mg} / 200 \mathrm{~g} \mathrm{bw})$ showed degenerated seminiferous tubules (black arrow). c The fetuses maternally treated with high-dose progesterone $(3.6 \mathrm{mg} / 200 \mathrm{~g} \mathrm{bw})$ show hemorrhage between the seminiferous tubules (black arrowhead) and congested blood vessels (CO), and most seminiferous tubules have an irregular degenerate (DT) pattern. $\mathbf{d}$ The ovary of the control has a normal architecture of well-developed primordial follicles (white arrow). e The fetuses maternally treated with low-dose progesterone show incomplete development of their sex cords into primordial follicles with mildly degenerated sex cords (white arrowhead) that exhibit hydropic degeneration of the epithelial tissue. $\mathbf{f}$ The fetuses maternally treated with high-dose progesterone show poorly developed ovaries with an atrophied sex cord (star). a The fetal rat cartilage of the control group has a normal chondrocyte. $\mathbf{b}$ The cartilage of the group maternally treated with low-dose progesterone shows normal cartilage histology. $\mathbf{c}$ The fetal rat cartilage maternally treated with high-dose progesterone shows hypertrophied chondrocytes (asterisks)

\section{Abbreviations}

ALP: Alkaline phosphatase; ANOVA: Analysis of variance; At: Atlas; ax: Axis; C: Crest; ca.v: Caudal vertebrae; CO: Congested blood vessels; CVL: Crown vertebral length; cv: Cervical vertebrae; DT: Degenerate pattern;

GD1: Gestation day 1; GD20: Gestation day 20; fi: Fibula; Fe: Femur; frb: Free ribs; H\&E: Hematoxylin and eosin stain; il: Ilium; IT: Interstitial tissue;

is: Ischium; KOH: Potassium hydroxide; Iv: Lumbar vertebrae; mc: Metacarpals; mt: Metatarsus; pa: Obturator foramen of patella; PBS: Phosphate-buffered saline; ph: Phalanges; re: Radial bone; SE: Seminiferous tubules; ssp: Scapular spine; sv: Sacral vertebrae; t: Tibia; ta: Tarsus; tv: Thoracic vertebrae; ue: Ulnar bone; xp: Xiphoid process

\section{Acknowledgements}

The authors would like to thank Dr. Said A. Hassan, Department of Anatomy, Faculty of Veterinary Medicine, Suez Canal University, Egypt, for his kind assistance in interpreting the results of the histopathological analysis of the sections.

\section{Authors' contributions}

HT and RE conceived and designed the experiments. HT and HA performed the experiments. RE, HA, and MA wrote the paper. HE revised the manuscript. All authors read and approved the final manuscript.

\section{Funding}

The authors received no financial support for the research, authorship, and/ or publication of this article.

\section{Availability of data and materials}

All the data involved from this study is included in the paper and can be obtained from the corresponding author upon request approval.

\section{Ethics approval and consent to participate}

The procedures of the current study were carried out based on the ethical guidelines for the use of animals in laboratory experiments of the Faculty of Veterinary Medicine, Suez Canal University, Egypt (Approval number \#2019016).

\section{Consent for publication}

"Not applicable"

\section{Competing interests}

"Not applicable"

\section{Author details}

'Department of Zoology, Faculty of Science, Suez Canal University, Ismailia, Egypt. ${ }^{2}$ Department of Biology, College of Science and Art, University of Jeddah Branch of Khulais Governorate-Girls Section, Jeddah, Saudi Arabia. ${ }^{3}$ Department of Forensic Medicine and Toxicology, Faculty of Veterinary Medicine, Suez Canal University, Ismailia, Egypt. ${ }^{4}$ Department of Physiology, Faculty of Veterinary Medicine, Suez Canal University, Ismailia, Egypt. 
Received: 29 April 2020 Accepted: 15 February 2021 Published online: 06 March 2021

\section{References}

Alborzi, A., Mac, K., Glackin, C., Murray, S., \& Zernik, J. H. (1996). Endochondral and intramembranous fetal bone development: Osteoblastic cell proliferation, and expression of alkaline phosphatase, m-twist, and histone H4. Journal of Craniofacial Genetics and Developmental Biology, 16(2), 94-106.

Augustine, R. A., Ladyman, S. R., \& Grattan, D. R. (2008). From feeding one to feeding many: Hormone-induced changes in bodyweight homeostasis during pregnancy. The Journal of Physiology, 586(2), 387-397. https://doi. org/10.1113/jphysiol.2007.146316.

Bancroft, J. D., \& Gamble, M. (2008). Theory and practice of histological techniques. Churchill Livingstone. Elsevier Health Sciences.

Bartholomeusz, R. K., \& Bruce, N. W. (1976). Effects of maternal progesterone supplementation on fetal, placental and corpus luteal weights in the rat. Biology of Reproduction, 15(1), 84-89. https://doi.org/10.1095/biolreprod1 5.1.84.

Bhatia, A. J., \& Wade, G. N. (1989). Progesterone can either increase or decrease weight gain and adiposity in ovariectomized Syrian hamsters. Physiology \& Behavior, 46(2), 273-278. https://doi.org/10.1016/0031-9384(89)90267-9.

Carmichael, S. L., Shaw, G. M., Laurent, C., Croughan, M. S., Olney, R. S., \& Lammer, E. J. (2005). Maternal progestin intake and risk of hypospadias. Archives of Pediatrics \& Adolescent Medicine, 159(10), 957-962. https://doi.org/10.1001/a rchpedi.159.10.957.

Check, J. H., Rankin, A., \& Teichman, M. (1986). The risk of fetal anomalies as a result of progesterone therapy during pregnancy. Fertility and Sterility, 45(4), 575-577. https://doi.org/10.1016/s0015-0282(16)49292-7.

Christenson, R. H. (1997). Biochemical markers of bone metabolism: An overview. Clinical Biochemistry, 30(8), 573-593. https://doi.org/10.1016/s0009-912 0(97)00113-6.

Chwalisz, K., Winterhager, E., Thienel, T., \& Garfield, R. E. (1999). Synergistic role of nitric oxide and progesterone during the establishment of pregnancy in the rat. Human Reproduction, 14(2), 542-552. https://doi.org/10.1093/ humrep/14.2.542.

Di Renzo, G. C., Mattei, A., Gojnic, M., \& Gerli, S. (2005). Progesterone and pregnancy. Current Opinion in Obstetrics and Gynecology, 17(6), 598-600. https://doi.org/10.1097/01.gco.0000191899.84567.4d.

Ekambaram, G., Kumar, S. K. S., \& Joseph, L. D. (2017). Comparative study on the estimation of estrous cycle in mice by visual and vaginal lavage method. Journal of clinical and diagnostic research: JCDR, 11(1), AC05-AC07. https://doi. org/10.7860/JCDR/2017/23977.9148.

Ellinwood, W. E., \& Resko, J. A. (1980). Sex differences in biologically active and immunoreactive gonadotropins in the fetal circulation of rhesus monkeys. Endocrinology, 107(4), 902-907. https://doi.org/10.1210/endo-107-4-902.

Faas, M. M., Melgert, B. N., \& de Vos, P. (2010). A brief review on how pregnancy and sex hormones interfere with taste and food intake. Chemosensory Perception, 3(1), 51-56. https://doi.org/10.1007/s12078-009-9061-5.

Figueiró-Filho, E. A., Aydos, R. D., Senefonte, F. R. d. A., Ferreira, C. M., Pereira, É. F. d. V., Oliveira, V. M. d., .. Bósio, M. A. C. (2014). Effects of enoxaparin and unfractionated heparin in prophylactic and therapeutic doses on the fertility of female Wistar rats. Acta Cirúrgica Brasileira, 29(7), 410-416. https://doi.org/1 0.1590/s0102-86502014000700001.

Garrett, J. E., Geisert, R. D., Zavy, M. T., \& Morgan, G. L. (1988). Evidence for maternal regulation of early conceptus growth and development in beef cattle. Journal of Reproduction and Fertility, 84(2), 437-446. https://doi.org/10.1 530/jrf.0.0840437.

Greenberg, G., Inman, W., Weatherall, J., Adelstein, A., \& Haskey, J. (1977). Maternal drug histories and congenital abnormalities. British Medical Journal, 2(6091), 853-856. https://doi.org/10.1136/bmj.2.6091.853.

Gutzwiller, J. P., Drewe, J., Ketterer, S., Hildebrand, P., Krautheim, A., \& Beglinger, C. (2000). Interaction between CCK and a preload on reduction of food intake is mediated by CCK-A receptors in humans. American Journal of Physiology. Regulatory, Integrative and Comparative Physiology, 279(1), R189-R195. https:// doi.org/10.1152/ajpregu.2000.279.1.R189.

Harel, Z., Johnson, C. C., Gold, M. A., Cromer, B., Peterson, E., Burkman, R., ... Bachrach, L. K. (2010). Recovery of bone mineral density in adolescents following the use of depot medroxyprogesterone acetate contraceptive injections. Contraception, 81(4), 281-291. https://doi.org/10.1016/j.contra ception.2009.11.003
Harini, C., Sainath, S. B., \& Reddy, P. S. (2009a). Progesterone administration induces preimplantation embryonic loss in mice. Fertility and Sterility, 91(5 Suppl), 2137-2141. https://doi.org/10.1016/j.fertnstert.2008.06.031.

Harini, C., Sainath, S. B., \& Reddy, P. S. (2009b). Recovery of suppressed male reproduction in mice exposed to progesterone during embryonic development by testosterone. Reproduction, 137(3), 439-448. https://doi.org/1 0.1530/REP-08-0438.

Janerich, D. T., Piper, J. M., \& Glebatis, D. M. (1974). Oral contraceptives and congenital limb-reduction defects. The New England Journal of Medicine, 291(14), 697-700. https://doi.org/10.1056/NEJM197410032911403.

Kezele, P., \& Skinner, M. K. (2003). Regulation of ovarian primordial follicle assembly and development by estrogen and progesterone: Endocrine model of follicle assembly. Endocrinology, 144(8), 3329-3337. https://doi.org/10.1210/ en.2002-0131.

Kricker, A., Elliott, J. W., Forrest, J. M., \& McCredie, J. (1986). Congenital limb reduction deformities and use of oral contraceptives. American Journal of Obstetrics and Gynecology, 155(5), 1072-1078. https://doi.org/10.1016/0002-93 78(86)90352-2.

Lammer, E. J., \& Cordero, J. F. (1986). Exogenous sex hormone exposure and the risk for major malformations. Journal of the American Medical Association, 255(22), 3128-3132. https://doi.org/10.1001/jama.1986.03370220090033.

Makris, S. L., Solomon, H. M., Clark, R., Shiota, K., Barbellion, S., Buschmann, J., ... Hazelden, K. P. (2009). Terminology of developmental abnormalities in common laboratory mammals (version 2). Birth Defects Research Part B: Developmental and Reproductive Toxicology, 86(4), 227-327.

Menegola, E., Broccia, M. L., \& Giavini, E. (2001). Atlas of rat fetal skeleton double stained for bone and cartilage. Teratology, 64(3), 125-133. https://doi.org/10.1 002/tera.1055.

Mohsen, S. M., Esfandiari, E., Rabiei, A. A., Hanaei, M. S., \& Rashidi, B. (2013). Comparing two methods of plastination and glycerin preservation to study skeletal system after Alizarin red-Alcian blue double staining. Advanced biomedical research, 2(2), 19-22. https://doi.org/10.4103/2277-9175.108003.

Paget, G., \& Barnes, J. (1964). Toxicity tests. In D. Laurence, \& A. Bacharach (Eds.) Evaluation of drug activities: Pharmacometrics, (vol. 1, pp. 135-165). London: Academic.

Piesta, A., Maj, T., \& Chelmonska-Soyta, A. (2009). The influence of mating on estrogen receptor alpha protein level in spleen and uterine macrophages in female mice. Reproductive Biology, 9(3), 225-240. https://doi.org/10.1016/s1 $642-431 \times(12) 60028-x$

Pointis, G., Latreille, M., Richard, M., D'Athis, P., \& Cedard, L. (1984). Effect of maternal progesterone exposure on fetal testosterone in mice. Biology of the Neonate, 45(4), 203-208. https://doi.org/10.1159/000242005.

Pointis, G., Latreille, M.-T., \& Cedard, L. (1980). Gonado-pituitary relationships in the fetal mouse at various times during sexual differentiation. The Journal of Endocrinology, 86(3), 483-488. https://doi.org/10.1677/joe.0.0860483.

Pointis, G., Latreille, M. T., Richard, M. O., D'Athis, P., \& Cedard, L. (1987). Effect of natural progesterone treatment during pregnancy on fetal testosterone and sexual behavior of the male offspring in the mouse. Developmental Pharmacology and Therapeutics, 10(5), 385-392. https://doi.org/10.1159/0004 57768.

Pushpalatha, T., Reddy, P. R., \& Reddy, P. S. (2003). Effect of prenatal exposure to hydroxyprogesterone on steroidogenic enzymes in male rats. Naturwissenschaften, 90(1), 40-43. https://doi.org/10.1007/s00114-002-0384-1.

Rajah, R., Glaser, E. M., \& Hirshfield, A. N. (1992). The changing architecture of the neonatal rat ovary during histogenesis. Developmental Dynamics : an Official Publication of the American Association of Anatomists, 194(3), 177-192. https:// doi.org/10.1002/aja.1001940303.

Resseguie, L. J., Hick, J. F., Bruen, J. A., Noller, K. L., O'Fallon, W. M., \& Kurland, L. T. (1985). Congenital malformations among offspring exposed in utero to progestins, Olmsted County, Minnesota, 1936-1974. Fertility and Sterility, 43(4), 514-519. https://doi.org/10.1016/s0015-0282(16)48490-6.

Rock, J. A., Wentz, A. C., Cole, K. A., Kimball Jr., A. W., Zacur, H. A., Early, S. A., \& Jones, G. S. (1985). Fetal malformations following progesterone therapy during pregnancy: A preliminary report. Fertility and Sterility, 44(1), 17-19. https://doi.org/10.1016/S0015-0282(16)48670-X.

Seegmiller, R. E., Nelson, G. W., \& Johnson, C. K. (1983). Evaluation of the teratogenic potential of delalutin (17 alpha-hydroxyprogesterone caproate) in mice. Teratology, 28(2), 201-208. https://doi.org/10.1002/tera.1420280208.

Telefo, P. B., Tagne, S. R., Koona, O. E. S., Yemele, D. M., \& Tchouanguep, F. M. (2012). Effect of the aqueous extract of Justicia insularis T. Anders (Acanthaceae) on ovarian folliculogenesis and fertility of female rats. African 
Journal of Traditional, Complementary, and Alternative Medicines, 9(2), 197203. https://doi.org/10.4314/ajtcam.v9i2.3.

Tovar, S. A., Seoane, L. M., Caminos, J. E., Nogueiras, R., Casanueva, F. F., \& Dieguez, C. (2004). Regulation of peptide YY levels by age, hormonal, and nutritional status. Obesity Research, 12(12), 1944-1950. https://doi.org/10.103 8/oby.2004.244.

Warren, M. P., \& Shantha, S. (1999). Uses of progesterone in clinical practice. International Journal of Fertility and Women's Medicine, 44(2), 96-103.

Yan, R., Nanovskaya, T. N., Zharikova, O. L., Mattison, D. R., Hankins, G. D., \& Ahmed, M. S. (2008). Metabolism of 17a-hydroxyprogesterone caproate by hepatic and placental microsomes of human and baboons. Biochemical pharmacology, 75(9), 1848-1857. https://doi.org/10.1016/j.bcp.2008.01.013.

Yassaee, F., Shekarriz-Foumani, R., Afsari, S., \& Fallahian, M. (2014). The effect of progesterone suppositories on threatened abortion: A randomized clinical trial. Journal of Reproduction \& Infertility, 15(3), 147-151.

\section{Publisher's Note}

Springer Nature remains neutral with regard to jurisdictional claims in published maps and institutional affiliations.

\section{Submit your manuscript to a SpringerOpen ${ }^{\circ}$ journal and benefit from:}

- Convenient online submission

- Rigorous peer review

- Open access: articles freely available online

High visibility within the field

- Retaining the copyright to your article

Submit your next manuscript at $\boldsymbol{\nabla}$ springeropen.com 